\title{
Rapid and reliable detection of CD44 variants in gastric carcinoma using a nested reverse transcription-polymerase chain reaction
}

\author{
YAN WANG $^{1}$, YUHONG LIU $^{1}$ and BAI XIAO ${ }^{2}$ \\ Departments of ${ }^{1}$ Gastroenterology and ${ }^{2}$ Experimental Medicine, \\ Beijing Chao Yang Hospital Affiliated to Capital Medical University, Beijing 100020, P.R. China
}

Received July 16, 2014; Accepted March 27, 2015

DOI: $10.3892 / 01.2015 .3664$

\begin{abstract}
The present study aimed to establish a rapid and reliable method for detecting the expression of cluster of differentiation 44 variant $(\mathrm{CD} 44 \mathrm{v})$ in gastric carcinoma, and to investigate the significance of CD44v in gastric carcinoma. Using a nested reverse transcription-polymerase chain reaction ( $\mathrm{RT}-\mathrm{PCR}$ ) technique, the expression of CD44v and CD44v8-10 was analyzed in gastric cancer tissues (128 cases), precancerous lesions (19 cases of atypical hyperplasia and 6 cases of intestinal metaplasia) and corresponding adjacent non-cancerous tissues (153 cases). The tumor and non-cancerous biopsy samples of 153 patients were analyzed using nested RT-PCR. All the PCR products included bands at $482 \mathrm{bp}$, demonstrating positive CD44 expression. By contrast, the CD44v band (>600 bp) was observed in 132/153 total tumor samples (86.3\%), including $114 / 128$ gastric cancer samples $(89.1 \%), 16 / 19$ atypical hyperplasia samples $(84.2 \%)$ and $2 / 6$ intestinal metaplasia samples $(33.3 \%)$. However, 18/153 non-cancerous tissues samples $(11.8 \%)$ exhibited a CD44v band. Thus, CD44v expression was significantly higher in gastric cancer tissues and precancerous lesions compared with that of adjacent non-cancerous tissues $(\mathrm{P}<0.05)$. Furthermore, there was a significant difference in CD44v8-10 expression detected between gastric cancer and adjacent non-cancerous tissue samples $(\mathrm{P}<0.05)$. Among the 25 patients with precancerous lesions, 8/19 atypical hyperplasia cases and 1/6 intestinal metaplasia cases were positive for CD44v8-10 expression. The difference in the CD44v8-10 expression rate among the various pathological types of gastric cancer $(n=128)$ cases was
\end{abstract}

Correspondence to: Dr Yuhong Liu, Department of Gastroenterology, Beijing Chao Yang Hospital Affiliated to Capital Medical University, 8 Gongren Tiyuchang Nanlu, Beijing 100020, P.R. China

E-mail: yuhongliu@yeab.net

Key words: cluster of differentiation 44 variants, gastric carcinoma, nested reverse transcription-polymerase chain reaction not significant $(\mathrm{P}>0.05)$. Additionally, immunohistochemical analysis identified CD44v positivity (++) in 59/76 (77.6\%) cases of gastric cancer and 5/12 (41.1\%) cases of atypical hyperplasia. The CD44v and CD44v8-10 PCR products were confirmed by sequencing analysis. The results of the present study indicated that nested RT-PCR technology may be exploited as a method for gastric carcinoma diagnosis.

\section{Introduction}

Gastric carcinoma is one of the most common gastrointestinal malignant tumors worldwide. It develops through a multifactorial, multistage process resulting from an imbalance between oncogenes and tumor suppressor genes. The global five-year survival rate for gastric carcinoma is $<10 \%$ (1) and cancer cell metastasis is the major reason for gastric carcinoma lethality (2). Metastasis and proliferation rely on a series of interactions between tumor cells and the extracellular matrix, as well as other cells (3). In addition, tumor cell surface adhesion molecules may have a significant role in this process $(2,3)$.

Cluster of differentiation 44 (CD44) is an integral cell membrane glycoprotein with a molecular weight of $85-250 \mathrm{kD}$. CD44 was initially identified as a lymphocyte homing receptor on circulating lymphocytes, and exhibits homing, adhesion and migration functions (4). The CD44 protein exists in various isoforms [variants 1-10 (v1-10)] generated from the primary transcript by the alternate splicing of 10 exons. The generation of CD44 splice variants is hypothesized to be closely associated with gastric carcinoma tumorigenesis and differentiation $(5,6)$. For example, it has been reported that the formation and metastasis of gastric carcinoma cells promoted by CD44 is associated with the CD44v adherence function (7). Cancer cells expressing CD44v are able to utilize a camouflage function against lymphocytes to escape identification and destruction by the human immune system, thus, enabling easier metastasis (8). Among these CD44 variants, CD44v8-10 expression is considered to be a prognostic indicator of gastric carcinoma (9). A previous study of gastric cancer evaluated the expression of standard CD44 (CD44s) (10), while other studies have investigated the expression of the CD44v8-10 isoform or CD44s and 
CD44v (11-15). The study utilized antibodies against CD44s, an isoform lacking all variant exons that is widely expressed in lymphoid and non-lymphoid tissues.

In the present study, reverse transcription-polymerase chain reaction (RT-PCR) combined with nested PCR technology (nested RT-PCR) was used to detect CD44 mRNA expression in 153 dual biopsy samples obtained during gastroscopy (one sample was obtained from the lesion and one from the corresponding adjacent non-cancerous tissue). Pathologically diagnosed gastric carcinoma and atypical hyperplasia tissues were subsequently subjected to immunohistochemical analysis, to investigate the value of nested RT-PCR for the early diagnosis and prognosis of patients with gastric cancer or precancerous lesions.

\section{Materials and methods}

Reagents and antibodies. The RNA isolation kit and RT-PCR kit were purchased from Promega Corp. (Madison, WI, USA). The monoclonal mouse anti-human CD44v antibody (cat. no. SM1126F) was obtained from Acris Antibodies GmbH (Herford, Germany) and the streptavidin-peroxidase immunohistochemistry kit was obtained from Santa Cruz Biotechnology, Inc. (Dallas, TX, USA). The DNA quick purification kit was from Biodev-Tech Scientific and Technical Co., Ltd (Beijing, China). All other chemicals were purchased from DAAN Gene Co., Ltd of Sun Yat-Sen University (Guangzhou, China), unless otherwise stated.

Sample preparations and pathological diagnosis. The present study included 153 patients (108 males and 45 females; mean age, 65.4 \pm 16.7 years) who underwent a gastroscopic examination in the Beijing Chao Yang Hospital (Beijing, China) between March 2009 and April 2012. During the procedure, 6-8 tumor tissue biopsies and 3-4 corresponding adjacent non-cancerous tissue biopsies were obtained from each patient. The samples were immediately frozen and stored at $-80^{\circ} \mathrm{C}$ prior to use. Pathological examination diagnosed 128 cases of gastric cancer, including 56 cases of well-differentiated adenocarcinoma, 40 cases of poorly differentiated adenocarcinoma and 32 cases of mucinous carcinoma (16). Furthermore, 25 patients exhibited precancerous lesions, including 19 cases of atypical hyperplasia and 6 cases of intestinal metaplasia (Table I). The present study was approved by the Ethics Committee of Beijing Chao Yang Hospital Affiliated to Capital Medical University, and written informed consent was obtained from all patients.

Nested RT-PCR. All primers were synthesized by Beijing SBS Genetech Co., Ltd (Beijing, China), as described by Matsumura and Tarin (17). The primer sequences were as follows: Forward, 5'-GACACATATTGCTTCAATGCTTCAGC-3' and reverse, 5'-GATGCCAAGATGATCAGCCATTC TGGAAT-3' for full-length CD44s (482-bp PCR product); forward, 5'-CCTGAAGAAGATTGTACATACGTCACA GAC-3' and reverse, 5'-TGTCCTTATAGGACCAGA-3' for nested PCR (417-bp PCR product); and forward, 5'-ATGGA CTCCAGTCATAGTACAACG-3' and reverse, 5'-TAAGG AACGATTGACATTAGAG-3' for CD44V8-10 (396-bp PCR product) (18). Total RNA was extracted using the acid-guanidinium-phenol-chloroform method (19), according
Table I. Pathological diagnoses of 153 patients with gastric cancer $(n=128)$ and precancerous lesions $(n=25)$.

Pathological diagnosis

Patients, $\mathrm{n}$

Gastric cancer

Well-differentiated adenocarcinoma

56

Poorly differentiated adenocarcinoma

40

Mucinous carcinoma

32

Precancerous lesion

Atypical hyperplasia

19

Intestinal hyperplasia

6

Figure 1. Agarose gel electrophoresis map of RT-PCR and nested PCR products. Lanes 1, 4 and 7: Cluster of differentiation 44 variants ( $>600 \mathrm{bp})$ and standard CD44 (417 bp) RT-PCR products. Lanes 2, 3, 5, 6, 8 and 9: Nested RT-PCR products of samples 1, 4 and 7. Lane 10: ФX174/Hae III DNA standard. RT-PCR, reverse transcription-polymerase chain reaction.

to the manufacturer's instructions. Subsequently, RT-PCR was conducted in accordance with the manufacturer's instructions. Briefly, $20 \mu \mathrm{l}$ RT reaction mixture [containing $1 \mu \mathrm{g}$ total RNA, 100 ng Oligo dT (15mer), 50 mmol/1 Tris- $\mathrm{HCl}$ (pH 8.3), $3.75 \mathrm{mmol} / 1 \mathrm{KCl}, 3 \mathrm{mmol} / 1 \mathrm{MgCl}_{2}, 10 \mathrm{mmol} / 1 \mathrm{DTT}, 500 \mu \mathrm{mol} / \mathrm{l}$ of each dNTP, $25 \mathrm{U}$ M-MLV reverse transcriptase and $20 \mathrm{U}$ RNasin] was added to $20 \mu \mathrm{l}$ PCR Master Mix. The mixture was initially denatured at $94^{\circ} \mathrm{C}$ for $5 \mathrm{~min}$, and then subjected to 30 cycles of $94^{\circ} \mathrm{C}$ for $1 \mathrm{~min}, 55^{\circ} \mathrm{C}$ for $1 \mathrm{~min}$ and $72^{\circ} \mathrm{C}$ for 1 min. $\beta$-actin was used as the internal control, and nested PCR was performed immediately following RT-PCR using the RT-PCR product as the template and the same primers as described previously.

Sequencing analysis of PCR products. The PCR products were separated on $1.8 \%$ agarose gels and stained with ethidium bromide $(10 \mu \mathrm{g} / \mathrm{ml})$. Notable bands were excised from the gel, recovered and purified using the Wizard ${ }^{\circledR} \mathrm{SV}$ Gel and PCR Clean-Up System (Promega Corp.), according to the kit manual. The purified PCR products were sequenced using the 5'-AGACCAAGACACATTCAA-3' primer and an ABI 373A DNA sequencer (Applied Biosystems Life Technologies, Foster City, CA, USA). 
Table II. CD44v expression in gastric tumor, precancerous lesion and non-cancerous tissue samples.

\begin{tabular}{lcrr}
\hline & & & CD44v positive \\
\cline { 3 - 4 } Pathological diagnosis & Total cases, $\mathrm{n}$ & $\mathrm{n}$ & \\
\hline Gastric cancer & 128 & 114 & 89.1 \\
Precancerous lesion & & 16 & 84.2 \\
Atypical hyperplasia & 6 & 2 & 33.3 \\
Intestinal metaplasia & 193 & 18 & 11.8 \\
Adjacent non-cancerous tissues & 153 & 16 \\
\hline
\end{tabular}

CD44v, cluster of differentiation 44 variants.

Table III. CD44v8-10 expression in gastric tumor and adjacent non-cancerous tissue samples.

CD44v8-10 positive

\begin{tabular}{lccr}
\cline { 3 - 4 } Pathological diagnosis & Total cases, $\mathrm{n}$ & $\mathrm{n}$ & $\mathrm{Rate}, \%$ \\
\hline Gastric cancer & 128 & 97 & 75.8 \\
Adjacent non-cancerous tissues & 128 & 14 & 10.9 \\
\hline
\end{tabular}

CD44v, cluster of differentiation 44 variants.

Table IV. CD44v and CD44v8-10 expression in various pathological types of gastric cancer.

\begin{tabular}{|c|c|c|c|c|c|c|}
\hline \multirow[b]{2}{*}{ Gastric cancer type } & \multirow[b]{2}{*}{ Total cases, $\mathrm{n}$} & \multicolumn{2}{|c|}{ CD44v positive } & \multicolumn{2}{|c|}{ CD44v8-10 positive } & \multirow{2}{*}{$\begin{array}{c}\text { Cumulative } \\
\text { rate, } \%\end{array}$} \\
\hline & & $\mathrm{n}$ & Rate, $\%$ & $\mathrm{n}$ & Rate, $\%$ & \\
\hline Well-differentiated adenocarcinoma & 56 & 50 & 89.3 & 42 & 75.0 & 84.0 \\
\hline Poorly differentiated adenocarcinoma & 40 & 36 & 90.0 & 32 & 80.0 & 88.0 \\
\hline Mucinous carcinoma & 32 & 28 & 87.5 & 23 & 71.9 & 82.1 \\
\hline
\end{tabular}

CD44v, cluster of differentiation 44 variants.

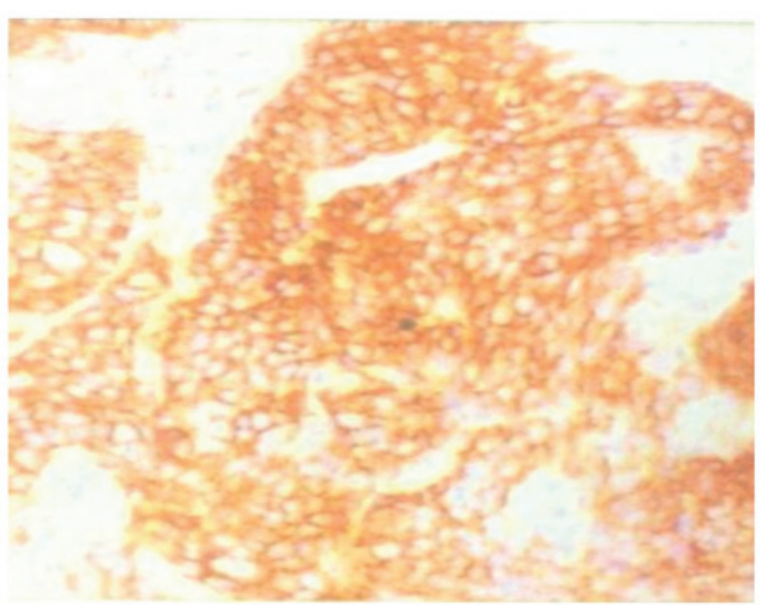

Figure 2. Representative immunohistochemical image of positive CD44v staining. Tumor tissue exhibiting positive CD44v expression in the cell membrane.
Immunostaining assay. Seventy-six gastric cancer samples and 12 atypical hyperplasia samples that exhibited a strong PCR band (CD44v; 600 bp), were selected to undergo immunohistochemical analysis. Paraffin-embedded sections $(4-\mu \mathrm{m})$ were deparaffinized, rehydrated and blocked for endogenous peroxidase activity. The sections were incubated with primary CD44v monoclonal antibodies at a dilution of 1:200 overnight at $4^{\circ} \mathrm{C}$. Following washing three times in Tris-buffered saline, the sections were incubated with horseradish peroxidase-labeled immunoglobulin $\mathrm{G}$ for $2 \mathrm{~h}$ at room temperature. Immunoreactive complexes were detected using ImmunoCruz ${ }^{\mathrm{TM}}$ mouse ABC Staining System (Santa Cruz Biotechnology, Inc.) prior to counterstaining the slides with hematoxylin. Cells stained brown in the membrane or cytoplasm were considered positive. The immunostaining was graded based on the percentage of positive cells observed, as follows: Negative $(-),<10 \%$; weak positive $(+), 10-25 \%$; positive $(++), 25-50 \%$; strong positive $(+++),>50 \%(20)$. 
Statistical analysis. All data were analyzed using the SPSS statistical package for Windows (version 10.0; SPSS, Inc., Chicago, IL, USA). The $\chi^{2}$ test was used to determine statistically significant differences among the groups. $\mathrm{P}<0.05$ was considered to indicate a statistically significant difference.

\section{Results}

As indicated in Fig. 1, the nested RT-PCR products obtained from the biopsy samples (tumor and non-cancerous) of 153 patients all exhibited 482 bp CD44 bands. The CD44v band ( $>600 \mathrm{bp}$ ) was observed in 132/153 total tumor samples (86.3\%), including 114/128 gastric cancer samples (89.1\%), 16/19 atypical hyperplasia samples $(84.2 \%)$ and $2 / 6$ intestinal metaplasia samples (33.3\%). Furthermore, the CD44v band was only observed in $18 / 153$ non-cancerous tissue samples (11.8\%).

$\mathrm{CD} 44 \mathrm{v}$ expression was significantly higher in gastric cancer tissues and precancerous lesions compared with that in non-cancerous tissues $(\mathrm{P}<0.05$; Table II). In addition, there was a significant difference in CD44v8-10 expression between gastric cancer tissue and adjacent non-cancerous tissues $(\mathrm{P}<0.05$; Table III). Among the 25 patients with precancerous lesions, $\mathrm{CD} 44 \mathrm{v} 8-10$ expression was positive in 8/19 atypical hyperplasia cases and 1/6 intestinal metaplasia cases. Furthermore, no significant difference was identified in CD44v8-10 expression rate between the various pathological types of gastric cancer ( $\mathrm{P}>0.05$; Table IV).

To verify the nested RT-PCR results, 76 gastric cancer samples and 12 atypical hyperplasia samples were examined by immunohistochemical staining (data not shown). The sections were CD44v-positive (++) in 59/76 (77.6\%) cases of gastric cancer and 5/12 cases of atypical hyperplasia (Fig. 2). To compare the immunostaining and nested RT-PCR data, the CD44v and CD44v8-10 PCR products were confirmed by sequencing analysis.

\section{Discussion}

Previous studies identified that CD44 messenger (m)RNA expression markedly varied between healthy and carcinomatous tissues, particularly with respect to the number, size and signal intensity of amplified PCR bands. In all tumor tissues analyzed, the amplified bands exhibited strong signals, high molecular weights and a relatively uniform distribution (21-23). Therefore, the abnormal differential expression of CD44 may be used to distinguish between carcinomatous gastric tissues and healthy gastric mucosa. Furthermore, abnormal expression of CD44 mRNA was determined to be relatively high irrespective of whether the gastric carcinoma tissues were highly or poorly differentiated $(24,25)$. A number of studies have proposed that the role of $\mathrm{CD} 44 \mathrm{v}$ in enhancing the infiltration and metastasis of tumor cells may be associated with its ability to alter the structure and function of cell surface adhesion molecules $(10,26)$. Miwa et al $(27)$ revealed that gastric carcinoma tissues exhibited higher CD44v expression compared with that of adjacent healthy tissues, with $76.6 \%$ (23/30 cases) positive expression. In addition, a Chinese study detected the expression of CD44v in gastric carcinoma tissue samples using RT-PCR technology and determined that CD44v expression was as high as $80.0 \%$ (16/20) (28). In the present study, RT-PCR was performed in combination with nested PCR, whereby the initial RT-PCR product was used as the template for nested $\mathrm{PCR}$, to detect CD44v expression. A positive expression rate of $86.3 \%$ (132/153 cases) was obtained, marginally higher than the aforementioned expression rates.

$\mathrm{CD} 44 \mathrm{v}$ expression appears to be significantly higher in metastasized gastric cancer compared with that of the primary tumor. According to currently available literature, positive CD44v8-10 expression may be an indication of metastasis and poor clinical prognosis (17). Furthermore, the survival rate was significantly lower in gastrointestinal malignant cancer patients with positive CD44v8-10 expression compared with patients not exhibiting CD44v8-10 expression $(9,29)$. Therefore, CD44v8-10 expression may be considered an important indicator of gastric carcinoma metastasis.

In the present study, RT-PCR combined with nested PCR revealed that the positive rate of $C D 44 \mathrm{v}$ expression in all the investigated lesions was $86.3 \%$ (132/153 cases). Of these cases, 128 were gastric carcinoma specimens, with 114 cases (89.1\%) exhibiting positive $\mathrm{CD} 44 \mathrm{v}$ expression. In addition, 25 cases were diagnosed as precancerous lesions (including 19 cases of atypical hyperplasia and 6 cases of intestinal metaplasia), with positive CD44v rates of $84.2 \%$ (16/19 cases) and 33.3\% (2/6 cases), respectively. Among the 153 healthy adjacent gastric mucosa specimens, 18 cases (11.8\%) exhibited positive CD44v expression. Furthermore, CD44v8-10 expression was observed in 97 cases of gastric cancer, resulting in rates of $85.1 \%$ (97/114) of the CD44v positive gastric carcinoma cases and 75.8\% (97/128) of the total gastric carcinoma cases. These values are higher than those reported previously, indicating that the combination of RT-PCR and nested PCR may improve the detection sensitivity of CD44v compared with current techniques, including RT-PCR alone. Using RT-PCR and nested PCR in combination increases the number of rounds of amplification performed and thus, we hypothesize that this achieves a higher level of sensitivity. In addition, it was identified that CD44v expression was not associated with pathological disease type.

Previous studies have typically employed RT-PCR combined with Southern blot hybridization or immunohistochemical techniques to detect CD44v and CD44v8-10 (30,31). However, in the present study, nested RT-PCR was combined with immunohistochemical analysis of 76 cases of gastric carcinoma and 12 cases of atypical hyperplasia. The positive rate of CD44v reported using nested RT-PCR in the present study was significantly higher than the positive rates detected in previous studies $(9,10,25,30)$, however, the possibility of false positives was not considered. Furthermore, the use of RT-PCR with nested PCR as opposed to Southern blot hybridization resulted in experimental results that were confirmed by DNA sequencing. In particular, the detection rate and sensitivity of CD44v was markedly improved. Additionally, the nested RT-PCR method is simple and quick, does not require radioisotopes, and uses samples that are easily obtained from endoscopic examination. Therefore, nested RT-PCR represents a promising technique for the widespread evaluation of gastropathies, for the detection of gastric carcinoma.

\section{References}

1. Orditura M, Galizia G, Sforza V, et al: Treatment of gastric cancer. World J Gastroenterol 20: 1635-1649, 2014. 
2. Wielenga VJ, Heider KH, Offerhaus GJ, et al: Expression of CD44 variant proteins in human colorectal cancer is related to tumor progression. Cancer Res 53: 4754-4756, 1993.

3. Hsu KH, Tsai HW, Shan YS and Lin PW: Significance of CD44 expression in gastrointestinal stromal tumors in relation to disease progression and survival. World J Surg 31: 1438-1444, 2007.

4. Quiding-Järbrink M, Ahlstedt I, Lindholm C, Johansson EL and Lönroth H: Homing commitment of lymphocytes activated in the human gastric and intestinal mucosa. Gut 49: 519-525, 2001

5. East JA and Hart IR: CD44 and its role in tumour progression and metastasis. Eur J Cancer 29A: 1921-1922, 1993.

6. Herrlich P, Zöller M, Pals ST and Ponta H: CD44 splice variants: Metastases meet lymphocytes. Immunol Today 14: 395-399, 1993.

7. Xin Y, Grace A, Gallagher MM, Curran BT, Leader MB and Kay EW: CD44V6 in gastric carcinoma: A marker of tumor progression. Appl Immunohistochem Mol Morphol 9: 138-142, 2001.

8. Finn L, Dougherty G, Finley G, Meisler A, Becich M and Cooper DL: Alternative splicing of CD44 pre-mRNA in human colorectal tumors. Biochem Biophys Res Commun 200: 1015-1022, 1994.

9. Yamaguchi A, Saito M, Gio T, et al: Expression of CD44 variant exons 8-10 in gastric cancer. Jpn J Cancer Res 86: 1166-1171, 1995.

10. Ghaffarzadehgan K, Jafarzadeh M, Raziee HR, et al: Expression of cell adhesion molecule CD44 in gastric adenocarcinoma and its prognostic importance. World J Gastroenterol 14: 6376-6381, 2008.

11. Yamaguchi A, Goi T, Yu J, et al: Expression of CD44v6 in advanced gastric cancer and its relationship to hematogenous metastasis and long term prognosis. J Surg Oncol 79: 230-235, 2002.

12. Sasaki JI, Tanabe KK, Takahashi K, et al: Expression of CD44 splicing isoforms in lung cancers: Dominant expression of CD44v8-10 in non-small cell lung carcinomas. Int J Oncol 12: 525-533, 1998

13. Ahn MJ, Noh YH, Yoon HJ, et al: Detection of malignant cells in pleural fluid or ascites by CD44v8-10/CD44v10 competitive RT-PCR. Korean J Int Med 16: 30-35, 2001.

14. Miyake H, Eto H, Arakawa S, Kamidono S and Hara I: Over expression of CD44V8-10 in urinary exfoliated cells as an independent prognostic predictor in patients with urothelial cancer. $J$ Urol 167: 1282-1287, 2002.

15. Lau WM, Teng E, Chong HS, et al: CD44v8-10 is a cancer-specific marker for gastric cancer stem cells. Cancer Res 74: 2630-2641, 2014.

16. Hu B, El Hajj N, Sittler S, Lammert N, Barnes R and Meloni-Ehrig A: Gastric cancer: Classification, histology and application of molecular pathology. J Gastrointest Oncol 3: 251-261, 2012
17. Matsumura Y and Tarin D: Significance of CD44 gene products for cancer diagnosis and disease evaluation. Lancet 340 : 1053-1058, 1992.

18. Takeuchi K, Yamaguchi A, Urano T, Goi T, Nakagawara G and Shiku H: Expression of CD44 variant exons 8-10 in colorectal cancer and its relationship to metastasis. Jpn J Cancer Res 86: 292-297, 1995

19. Chomczynski P and Sacchi N: Single-step method of RNA isolation by acid guanidinium thiocyanate-phenol-chloroform extraction. Anal Biochem 162: 156-159, 1987.

20. Mathew J, Hines JE, Obafunwa JO, Burr AW, Toole K and Burt AD: CD44 is expressed in hepatocellular carcinomas showing vascular invasion. J Pathol 179: 74-79, 1996.

21. Haynes BF, Telen MJ, Hale LP and Denning SM: CD44 - a molecule involved in leukocyte adherence and T-cell activation. Immunol Today 10: 423-428, 1989.

22. Mackay CR, Terpe HJ, Stauder R, Marston WL, Stark H and Günthert U: Expression and modulation of CD44 variant isoforms in humans. J Cell Biol 124: 71-82, 1994

23. Shiozaki H, Oka H, Inoue M, Tamura S and Monden M: E-cadherin mediated adhesion system in cancer cells. Cancer 77 (Suppl): S1605-S1613, 1996.

24. Wang T, Ong CW, Shi J, et al: Sequential expression of putative stem cell markers in gastric carcinogenesis. Br J Cancer 105: 658-665, 2011

25. Yokozaki H, Ito R, Nakayama $H$, Kuniyasu H, Taniyama $K$ and Tahara E: Expression of CD44 abnormal transcripts in human gastric carcinomas. Cancer Lett 83: 229-234, 1994.

26. Takaishi S, Okumura T, Tu S, et al: Identification of gastric cancer stem cells using the cell surface marker CD44. Stem Cells 27: 1006-1020, 2009.

27. Miwa T, Watanabe A, Yamada Y, et al: Progression in gastric carcinoma relative to the ratio of CD44 epithelial variant transcript to CD44 hematopoietic variant transcript. Cancer 77: 25-29, 1996.

28. Chen GY and Wang DR: The expression and clinical significance of CD44v in human gastric cancers. World J Gastroenterol 6: 125-127, 2000.

29. Mayer B, Jauch KW, Günthert U, et al: De-novo expression of CD44 and survival in gastric cancer. Lancet 342: 1019-1022, 1993.

30. Miyake H, Okamoto I, Hara I, et al: Highly specific and sensitive detection of malignancy in urine samples from patients with urothelial cancer by CD44v8-10/CD44v10 competitive RT-PCR. Int J Cancer 79: 560-564, 1998.

31. Okamoto I, Morisaki T, Sasaki J, et al: Molecular detection of cancer cells by competitive reverse transcription-polymerase chain reaction analysis of specific CD44 variant RNAs. J Nat Cancer Inst 90: 307-315, 1998. 